"This is the peer reviewed version of the following article: Levasseur MA, Ferrari M, Mcllwaine S, Iyer SN. Peer-driven family support services in the context of first-episode psychosis: Participant perceptions from a Canadian early intervention programme. Early Intervention in Psychiatry. 2019 Apr;13(2):335-341., which has been published in final form at DOI: 10.1111/eip.12771. This article may be used for non-commercial purposes in accordance with Wiley Terms and Conditions for Use of Self-Archived Versions."

\title{
Peer-driven family support services in the context of first-episode psychosis: Participant perceptions from a Canadian early intervention programme
}

Running title: Family-peer support in first-episode psychosis

Mary Anne Levasseur ${ }^{1}$; Manuela Ferrari ${ }^{1}$; Sarah Mcilwaine ${ }^{1,2}$; Srividya Iyer ${ }^{1,2^{*}}$

1 Douglas Mental Health University Institute, Montreal, Canada

2 Department of Psychiatry, McGill University, Montreal, Canada

* Correspondence concerning this article should be addressed to Srividya lyer, PEPP-Montreal, Douglas Mental Health University Institute, Pavillon Burland - 6875 Blvd. LaSalle, H4H 1R3 Montreal, Canada. Email: srividya.iyer@mcgill.ca. To know more about family peer support, contact Mary Anne Levasseur, the family peer support group coordinator at maryanne.levasseur@gmail.com. 


\begin{abstract}
:
Aim: This paper aims to advance our understanding of the experience of participating in peer support groups for family members of persons with psychosis and to expand the scant body of literature on peer support in the context of early intervention services for psychosis. Such an examination is relevant because the implementation and uptake of family-focused interventions remain inconsistent in early intervention services, despite their proven benefits.
\end{abstract}

Methods: To enable family caregivers to support one another, a family peer support project was initiated at an early intervention service for psychosis in Montreal, Canada. A family peer support provider and researchers collaboratively designed and conducted this study to examine the experience of those who participated in family peer support groups. Forty-four family members completed an English or French online questionnaire. Thematic analysis was used to code responses to open-ended questions to unpack crucial elements of this peer support intervention.

Results: Three key themes were identified - the impact of psychosis on families; understanding and coping with psychosis through family peer support; and improving family peer support services. Mutual support through sharing experiences; gains in knowledge of the illness and its treatment; emotional support; and increased caregiving and self-care capacities and skills were identified as critical benefits of family peer support.

Conclusion: Family peer support can be an acceptable and cherished means of engaging and 
sustaining families and enhancing their caregiving skills. Its integration into early intervention services holds the promise of helping promote recovery and reducing caregiver burden.

Key words: Early intervention, peer support, family caregivers, youth, psychosis

\section{INTRODUCTION}

Family involvement has been linked with better symptomatic and functional outcomes in early psychosis (Lenior, Dingemans, Linszen, De Haan, \& Schene, 2001; Petrakis, Bloom, \& Oxley, 2014). Family interventions, including psychoeducation (Barbato \& D'avanzo, 2000) and behavioural family management (Falloon et al., 1982), are strongly associated with fewer relapses and hospitalizations; and improved service engagement, medication adherence, and recovery (Barbato \& D'Avanzo, 2000).

However, caring for youths with psychosis can profoundly impact families/carers (Bibou-Nakou, Dikaiou, \& Bairactaris, 1997; Jungbauer \& Angermeyer, 2002; Jungbauer, Stelling, Dietrich, \& Angermeyer, 2004; Lowyck et al., 2004). Having to quickly learn to cope with crises, navigate the healthcare system (Ferrari et al., 2015), advocate for loved ones, and monitor treatment (Boydell et al., 2014; McCann, Lubman, \& Clark, 2009), families often experience distress, selfblame, and fear for their loved ones' future (Boydell et al., 2014; McCann et al., 2009).

Family engagement and family-focused interventions are therefore strongly recommended in early intervention (EI) services for psychosis (McGorry, 2015). Although El services provide various family interventions, including psychoeducation, skills training, and multiple family group therapy (Gleeson et al., 2009; Lenior et al., 2001), their implementation remains 
inconsistent (Bucci, Berry, Barrowclough, \& Haddock, 2016; Eassom, Giacco, Dirik, \& Priebe, 2014; Leggatt \& Woodhead, 2016). At the well-established Canadian El service where this study was conducted, only $32 \%$ of families attended family psychoeducation sessions (lyer, Loohuis, Pawliuk, Joober, \& Malla, 2011).

Clearly, additional avenues are needed to support, engage, inform and equip families. An avenue whose value is increasingly acknowledged in mental healthcare is family peer support (Mental Health Commission of Canada, 2015; Heinssen, Goldstein, \& Azrin, 2014; MacCourt, 2013; McGorry, Killackey, \& Yung, 2008; Early Psychosis Guidelines Writing Group and EPPIC National Support Program, 2016). While family peer support can take many forms, its core principle is the provision of support to families/carers by persons with experience of caring for a loved one with a mental health problem. Peer support can be valuable in supporting families and enhancing their caregiving skills, even when service users expressly prohibit clinicians from contacting their families (Early Psychosis Guidelines Writing Group and EPPIC National Support Program, 2016).

To date, there has been limited examination of peer-led interventions for family members in El services for psychosis. There are less than a handful of published reports on family peer support initiatives in the El context (Leggatt \& Woodhead, 2016; Petrakis, Bloom, \& Oxley, 2014; Day, Starbuck, \& Petrakis, 2017). This paper seeks to expand that literature. Using qualitative methodology, we explored the experience of the participants of a family peer support project at a Canadian El service.

\section{METHOD}


The critical emancipatory paradigm informed this qualitative collaborative evaluation (Denzin, \& Lincoln, 2000). Like the constructivist paradigm, the critical emancipatory paradigm acknowledges that reality is constructed within a social-historical context. However, it uses the research inquiry to help members of a given community gain capacity to make meaningful and practical changes in their community, and/or develop initiatives that are important to them. The critical emancipatory paradigm adopts a dialectic stance on the researcher-participant interaction to promote shared responsibility and decision-making. This collaborative process aims to shift power dynamics. Under this paradigm, non-academic participants can take on leadership roles within a research project. Furthermore, the critical emancipatory paradigm uses experiential knowledge to shape research aims and processes, and to create tangible changes and actions. The first author of this manuscript (ML) has lived experience of caring for a loved one with psychosis. ML contacted researchers SI and MF with a desire to evaluate the family peer support intervention that she and others had implemented for more than five years at an El for psychosis. Starting with thus shaping this study's aims, ML contributed significantly to the implementation of the project, including design, analysis and drafting the manuscript.

\section{Setting}

This study was conducted at the Prevention and Early Intervention Program for Psychosis (PEPP), a Montreal-based early psychosis programme that sees approximately 60 new cases annually. PEPP offers a two-year protocol of assertive case management, psychosocial and family interventions, and pharmacological treatment (Iyer, Jordan, MacDonald, Joober, \& Malla, 2015). 


\section{Description and evolution of the family peer support intervention at PEPP}

In November 2011, SI, who at that time was PEPP's program coordinator, invited service users' family members to discuss the role of the family in treatment and recovery. Pursuant to this meeting, family members agreed to meet among themselves to initiate a peer-driven family support group. At the first such meeting in January 2012, the 20 family members in attendance decided to appoint a family member leader $(\mathrm{ML})$ to facilitate support group meetings. Since then, support group meetings have been held weekly or fortnightly to allow families to share experiences and insights about caring for a person with psychosis. These two-hour weeknight meetings are held at PEPP alternatingly in English and French. The family peer facilitator also occasionally offers individual telephonic or in-person support.

Five years after its initiation, we decided to reach out to family members who attended peer support meetings and/or showed interest in attending, to explore their experience with and the impact of family peer support. Below we provide basic statistics about the number of and attendance at meetings as a contextual backdrop to our qualitative evaluation.

A total of 103 family peer support group meetings were held from January 2012 to December 2016 (average number of meetings/year = 20; range = 16-29 meetings/year). They were led by the family member facilitator, with minimal staff involvement (e.g., occasional inputs when $\mathrm{ML}$ was supporting a family member dealing with a crisis). On average, 7.75 family members (related to different service users) attended each meeting (median and mode attendance $=7.5$ and 9, respectively; range $=3-16) .20$ new family members joined each year. Each family member attended 6.7 meetings on average (range $=1-66)$. 


\section{Data collection}

We gathered participants' feedback on the groups' structure, format, and overall experience, through a qualitative collaborative formative evaluation (Patton, 2015; Popping, 2015;

O'Sullivan, 2004). Different program evaluation approaches support the engagement of different stakeholders in the process, with the aim of enhancing the evaluation procedure. However, the participatory evaluation takes this a step further by allowing stakeholders to take on leadership roles during the evaluation process. Working with two family members, we designed 12 open-ended questions to capture families' perspectives on their experience of attending peer support meetings, and their suggestions for improving the peer programme. Questions covered the following themes: family situation before attending peer support meetings (e.g., Why did you decide to attend the first meeting?); overall experience of attending meetings (e.g., What did you find most helpful about attending family peer support meetings?); and meeting format and suggestions (e.g., Please share your suggestions to improve family peer support.). Six additional questions pertained to respondents' characteristics and meeting attendance.

The questions were presented in English or French through an online platform. A link to them was emailed in December 2016 to 74 family members who had attended or expressed interest in family peer support meetings in the past four years. Of the 44 who responded, 36 had attended meetings (see Table 1). To fully explore family peer support, including barriers to its uptake, we considered the responses of all family members, including eight who had not attended meetings. Of the two family members who helped co-design the questionnaire, one 
$(\mathrm{ML})$ did not complete it and the other did so, but anonymously.

\section{Data analysis}

Qualitative data from the open-ended questions were analysed in phases, as recommended by Braun and Clark (2006). In the first phase, all team members familiarised themselves with the data by reviewing transcriptions for accuracy, reading and rereading transcriptions, and noting initial ideas. The second phase was devoted to generating initial codes and the third to searching for themes. Specifically, pairs of team members independently read and reread the English (ML and MF) and French (SM and ML) text data; developed a preliminary coding scheme; and collated codes into potential themes. In phase 4, team members reviewed and discussed the themes, examining them in relation to the coded extracts and the overall data set/list of themes, to ensure that themes were coherent and distinct. Phase 5 was focused on defining and naming themes; and the sixth and final phase was devoted to the writing process, which allowed further refinement of the analysis in light of the study's objectives and existing literature.

Eschewing a theoretically-driven approach, themes were arrived at inductively as they were identified. The decision to not operate from any pre-chosen theoretical framework was driven by a desire to let the experiences of family members speak for themselves without being constrained or complexioned by researchers' preconceptions. This also made sense given the nascent state of the field of enquiry and the exploratory nature of this study. Several strategies were used to enhance the trustworthiness of the qualitative findings. Two family members reviewed the first draft of open-ended questions and provided suggestions on rewording 
and/or adding questions, enhancing our study's credibility and authenticity. Extensive notetaking and debriefing/discussion during data analysis additionally strengthened the criticality and integrity of our findings.

\section{RESULTS}

The data analysis process identified the following key themes - the impact of psychosis, understanding and coping with psychosis through family peer support, and improving peer support services - and are presented below with illustrative quotes from family members' responses (quotes translated from French appear in italics).

\section{The impact of psychosis on families}

Family members reported feeling worried and overwhelmed by having to navigate the system of care without enough knowledge about psychosis and its treatment. Many felt "isolated," "alone," "worried," "helpless," and "misunderstood" in the early phases of their loved ones' treatment. Some $(n=15)$ found it difficult to talk about their loved ones' illness and family situation with others, citing concerns about privacy and stigma.

"I felt and knew I could not reach out to family, considering distance, and that I also respected my child's wishes to keep what happened to him quiet. I desperately needed and wanted to be with other families who were experiencing same or similar situation."

"It was almost impossible because people have a notion that you just snap out of it... take a pill. Clearly, the general population does not understand these 
situations."

Lack of knowledge about the illness, fear for their loved ones' future, "distress," and a sense of isolation, seemed to paralyze family members and diminished their caregiving capacity.

"I find not knowing about an illness causes fear. Fear causes stress and panic.

The patient is going through so much and when their caregiver is in fear and panic that makes the patient worst. I was in a bad place with my son and his situation. I had hardly nothing to go on when it first happened...."

“...A very dark stage in my life, and I didn't know how to cope."

\section{Understanding and coping with psychosis through family peer support}

A. Gaining knowledge about the illness, its treatment, and coping strategies

Family members felt that meetings helped them learn about psychosis, its treatment, available resources, and the healthcare system.

"Within months of attending the PEPP Family Support, I was able to educate myself and to have knowledge on why my son was behaving the way he was and felt the way he did."

“...Sometimes I feel like doctors prescribing them are not listening to the patient. Family support gave me the courage to trust in what my son was telling me about how he felt on certain meds and I worked hard to make his doctor see/hear what my son was saying." 
Family members described learning to cope with the illness, to communicate better with their loved ones and the clinical team, and to handle crises. Peer support also offered some an opportunity to reflect on their attitudes around mental illness and parenting.

\footnotetext{
"The impact of the strategies I have learned has helped me doing the right thing at the right moment.... [In] a crisis, things feel overwhelming and you are so tired as a caregiver that you burn out fast. Having this support group has helped me tremendously. You don't have to explain; other caregivers understand you and offer support and guidance."
}

"It helped me to become less judgmental and more respectful of my son. Our ability to talk harmoniously greatly improved. My son knows that I love and care about him as do his siblings and other extended family members. My son contacts us more often...."

Some described how trust and relationships with loved ones that were eroded during the hepseeking process were gradually restored through peer support.

"I had to learn to have my son trust me. I also had to learn to trust his choices and to respect his choices. I had to give him space and watch so that he is guided to the right path. All this I learned from family support."

For some family members, peers came to represent 'expert knowledge' and became a source of "guidance by experienced people." 
"We learned so much and we respected each other. Without the help of the Family Support Counsellor [MAL], my son would not be where he is today. Today my son is taking his meds on his own and is starting to co-operate with his recovery team."

Some mentioned how, over time, the family support group facilitated the overall recovery process.

"It's been over 3 years now, and things are getting better. ... with the support group and the way I have been able to understand my son's situation, has helped my son tremendously. Yes, the work is his, but the knowledge and support that I provide in a non-fearful situation to him, is an added bonus."

\section{B. Gaining self-care skills and strategies}

Some found caring for their loved one while attending to the rest of the family and working extremely difficult. They felt that they lacked the space or time to express their own distress. Voicing these concerns during family peer meetings allowed caregivers to acknowledge the need for self-care.

"I learned that I have to take a step back and to take care of myself, to not put everything on my shoulders and to not let the illness take hold of my life."

Family members also spoke of learning to earmark personal time, to avoid self-pity and guilt, and "forgiving" themselves. 
"Though it requires an ongoing effort, I have learned to feel much less guilty about not being able to solve his difficulties."

"This is one of the most important parts, to survive and actually help someone experiencing mental health problems requires you to not burn out, give up or blame yourself, so a better sense of how to be realistic about the human limitations makes you revalue yourself again. That allows you to better support others, if you accept yourself as well."

Sustaining hope for recovery was identified as an important aspect of self-care. One family member said, "Learning to not give up, to not lose hope, gave me strength."

\section{Gaining emotional support}

Family peer support meetings offered an avenue for family members to cope with difficult emotions and "stay strong."

"I believe being part of group is fundamental to survive as caregiver. Hearing and sharing lifts weight off your body. After each meeting, I always felt a weight was lifted. I hope that each time I share my story that someone in the group was helped through my story. Because they sharing and listening helped me."

Being "listened to" was described as difficult but valued aspects of family peer support. One participant said, "Hearing and sharing experiences with other families which I valued tremendously and learned from. Knowing you are not alone somehow helps." Another remarked, "I hear about others' experiences that I thought were unique to my situation." 
Compassion and empathy were identified as underpinning meetings. Sharing was a powerful way for families to develop relationships, connect with one another, and maintain and improve caregiving, even though it occasionally provoked pessimism.

"Within months of attending the Family Support, ... my fear/panic diminished and I was empowered by knowledge and support. I was able to understand what my son was going through and I in return was able to comfort him instead of being anxious with him and [it] made our family situation better."

"To see that, based of the experience of others, my son could have been ill for life and even worsen."

\section{Improving family peer support services}

Most participants who had attended meetings (23 out of 36 ) did not identify any barriers to attending.

"I traveled from a great distance to come to PEPP through winter, spring, summer and fall. Sometimes you are so tired to get there, but once you are there, you feel empowered and get strength to continue with the caregiving."

Others (6 out of 36) identified times, work schedules, transportation, and caregiving responsibilities as barriers to attending meetings.

"The primary reason I did not attend was because one of us had to stay home so our adult child was not left alone, particularly in the early going." 
"A little difficult given the distance.... I could not be present for all meetings particularly if the weather and roads are difficult."

Respondents who had not attended any meetings $(n=8)$ identified caregiving responsibilities, transportation issues and work schedules as barriers to attending. Despite not having attended meetings, they highlighted the importance of sharing experiences with other family members. One said, "I believe it is a very valuable and helpful option for caregivers to share/exchange experiences and learn from one another."

Respondents' suggestions included having more frequent group meetings at varied times; more access to the family member facilitator; a peer initiative to aid during crises; technologyenabled access to peer services (e.g., "web-platform"); and more materials and theme-specific meetings to improve knowledge and caregiving skills. Family members also suggested creating a provincial network of family caregivers to strengthen advocacy efforts.

\section{CONCLUSION}

The onset of psychosis is a distressing time for families (McCann, Lubman, \& Clark, 2011) who experience stigma, shame, isolation, and loss (McGorry, 1998). Psychosis can negatively impact the lives and well-being of sufferers' families (Bibou-Nakou et al., 1997; Boydell et al., 2014; McCann et al., 2011). These difficulties were reflected in our family members' narratives of being ill-equipped, in terms of emotions, knowledge, and skills, to provide sustained and beneficial assistance to their loved ones. This inability often marred their relationships with their family member with psychosis. 
For many, peer support meetings provided a safe venue to share experiences. Sharing and listening to caregiving experiences at peer support meetings helped family members gain emotional support; acquire experiential knowledge about treatment and recovery; cope with distress; regain agency and confidence; and promote recovery.

Learning from peers is often an immediate and powerful source of knowledge that can promote self-awareness and confidence (Dennis, 2003). Our respondents reported gaining 'expert knowledge' and enhanced self-awareness, which helped them better assess their family's situation. The experiences of peers who were further along in their caregiving journey gave carers valuable insights into their own journey.

Overall, our findings suggest that the family peer support group promoted emotional resilience, hope, and a sense of belonging. It also evoked feelings of being accepted, cared for, empathized with, and respected, despite profound personal difficulties. This in turn enhanced family members' caregiving competency and coping skills.

To our knowledge, this is one of less than a handful of evaluations of family peer support in an El context (see Petrakis, Bloom, \& Oxley, 2014; Day, Starbuck, \& Petrakis, 2017). An earlier published report describes the family peer service at the Orygen El programme in Australia (Leggatt \& Woodhead, 2016). At Orygen, peer support was provided by formally trained family members who were employees. In contrast, PEPP's family member facilitator started as a volunteer whose sole qualification was lived experience. Later, she did receive formal peer support training and an honorarium. This difference is significant given the lack of consensus on whether peer support facilitators should be formally employed by the programmes they serve. 
Our findings are consistent with the qualitative work of Petrakis and colleagues (2014) which described how the 'Journey to Recovery' open-ended family psychoeducation-cum-support group intervention in Australia was able to reduce isolation, help carers feel heard, foster a sense of collective experience, increase knowledge and enhance skills among caregivers. The authors identified similar barriers to attending meetings (e.g., competing family and work commitments) as those noted in our study. In 2017, the same program was evaluated quantitatively to document the extent to which attendees developed increased understanding of psychosis and its associated aspects (Day et al., 2017). This group intervention for families and friends has been implemented for more than 10 years. It is facilitated by two clinicians with expertise in early psychosis and integrates both psychoeducation and peer support elements. A key distinction between this intervention and the one we are reporting on is that the latter is entirely family peer-led and has no staff involvement. Thus, it is even more remarkable that evaluations of both interventions similarly highlight the value placed by carers on the opportunity such interventions provide for social connection and for sharing stories in a safe space.

Our study has both strengths and limitations. Significantly for the Canadian context, our sample included English and French speakers. Over half the people we contacted responded to the survey. Importantly, we designed our evaluation and analysed our data in collaboration with family members. One limitation is that data were collected using an online self-report questionnaire. Those who elected to complete it may have been the ones who benefitted the most from meetings. 
While the peer model of care is well-established for many health conditions (e.g., cancer, diabetes, etc.), its use in mental health is limited (Davidson, Bellamy, Guy, \& Miller, 2012). Our findings suggest that family peer support is acceptable to and cherished by families. However, the relatively low uptake of our family peer support service highlights the need for better integrating and publicising such services. Though rigorous evaluations of family peer support are warranted, there is enough validation of its utility from the perspective of families to make it an essential element of El for psychosis.

\section{Acknowledgements}

We would like to thank Ms. Leah den Besten (a family member) for her inputs on the survey and a draft of the manuscript. We also would like to thank Céline Villemus for help with translating the survey in French. We would like to thank past and current key leaders at PEPP Dr. Ashok Malla, Dr. Ridha Joober, Dr. Jai Shah, Karen Goldberg, Emily Meadows, Sherezad Abadi, Kevin MacDonald, Ina Winkelmann, Amine Saadi and Chantal Fournier - for their support of the family peer support initiative. We also want to thank all family members who attended family peer support groups and responded to the survey. Finally, a special thanks goes to those PEPP service users who, despite their often arduous experience of first episode psychosis, understood the value of their family members attending peer support groups

\section{Funding}

Author S.M. received graduate student awards from ACCESS Open Minds, the Canadian Institutes of Health Research (CIHR) and the Fonds de Recherche du Quebec - Santé (FRQS). An unrestricted grant from Otsuka supported PEPP's family peer support initiative since 2013. Author S.I. has received salary awards from CIHR and FRQS. This research is part of a larger 
program of research in early intervention for psychosis and youth mental health supported by a CIHR Foundation Scheme (PI: Iyer). 


\section{References}

Adame, A. L., \& Leitner, L. M. (2008). Breaking out of the mainstream: The evolution of peer support alternatives to the mental health system. Ethical Human Psychology and Psychiatry, 10(3), 146162.

Barbato, A., \& D'Avanzo, B. (2000). Family interventions in schizophrenia and related disorders: a critical review of clinical trials. Acta psychiatrica scandinavica, 102(2), 81-97.

Bibou-Nakou, I., Dikaiou, M., \& Bairactaris, C. (1997). Psychosocial dimensions of family burden among two groups of carers looking after psychiatric patients. Social Psychiatry and Psychiatric Epidemiology, 32(2), 104-108.

Boydell, J., Onwumere, J., Dutta, R., Bhavsar, V., Hill, N., Morgan, C., . . Kuipers, E. (2014). Caregiving in first-episode psychosis: social characteristics associated with perceived 'burden'and associations with compulsory treatment. Early intervention in psychiatry, 8(2), 122-129.

Braun, V., \& Clarke, V. (2006). Using thematic analysis in psychology. Qualitative research in psychology, $3(2), 77-101$.

Bucci, S., Berry, K., Barrowclough, C., \& Haddock, G. (2016). Family interventions in psychosis: a review of the evidence and barriers to implementation. Australian Psychologist, 51(1), 62-68.

Canada, M. H. C. o. (2015). Taking the next step forward: Building a responsive mental health and addictions system for emerging adults: Mental Health Commission of Canada Commission de la santé mentale du Canada.

Davidson, L., Bellamy, C., Guy, K., \& Miller, R. (2012). Peer support among persons with severe mental illnesses: a review of evidence and experience. World Psychiatry, 11(2), 123-128.

Day, K., Starbuck, R., \& Petrakis, M. (2017). Family group interventions in an early psychosis program: A re-evaluation of practice after 10 years of service delivery. International Journal of Social Psychiatry, 63(5), 433-438.

Dennis, C.-L. (2003). Peer support within a health care context: a concept analysis. International journal of nursing studies, 40(3), 321-332.

Denzin, N. K., \& Lincoln, Y. S. (2000). Introduction: The discipline and practice of qualitative research. In N. K. Denzin \& Y. S. Lincoln (Eds.), Handbook of qualitative research (2nd ed., pp. 1-28). Thousand Oaks, CA: Sage.

Division, C. M. H. A. B. (2007). Peer support guide for parents of children or youth with mental health problems. Vancouver, BC.

Early Psychosis Writing Group \& EPPIC National Support Program. (2016). Australian clinical guidelines for early psychosis, 2nd edition update, 2016. Melbourne: Orygen, The National Centre of Excellence in Youth Mental Health.

Eassom, E., Giacco, D., Dirik, A., \& Priebe, S. (2014). Implementing family involvement in the treatment of patients with psychosis: a systematic review of facilitating and hindering factors. BMJ Open, 4(10), e006108.

Falloon, I. R., Boyd, J. L., McGill, C. W., Razani, J., Moss, H. B., \& Gilderman, A. M. (1982). Family management in the prevention of exacerbations of schizophrenia: a controlled study. New England Journal of Medicine, 306(24), 1437-1440.

Ferrari, M., Flora, N., Anderson, K. K., Tuck, A., Archie, S., Kidd, S., \& McKenzie, K. (2015). The African, Caribbean and European (ACE) Pathways to Care study: a qualitative exploration of similarities and differences between African-origin, Caribbean-origin and European-origin groups in pathways to care for psychosis. BMJ Open, 5(1), e006562.

Gleeson, J., Cotton, S. M., Alvarez-Jimenez, M., Wade, D., Gee, D., Crisp, K., . . Castle, D. (2009). A randomized controlled trial of relapse prevention therapy for first-episode psychosis patients. The Journal of clinical psychiatry, 70(4), 477-486. 
Heinssen, R., Goldstein, A., \& Azrin, S. (2014). Evidence-based treatments for first episode psychosis: components of coordinated specialty care. White paper. Bethesda: National Institute of Mental Health.

Iyer, S., Jordan, G., MacDonald, K., Joober, R., \& Malla, A. (2015). Early intervention for psychosis: a Canadian perspective. The Journal of nervous and mental disease, 203(5), 356-364.

Iyer, S., Loohuis, H., Pawliuk, N., Joober, R., \& Malla, A. K. (2011). Concerns reported by family members of individuals with first-episode psychosis. Early intervention in psychiatry, 5(2), 163-167.

Jungbauer, J., Stelling, K., Dietrich, S., \& Angermeyer, M. C. (2004). Schizophrenia: problems of separation in families. Journal of advanced nursing, 47(6), 605-613.

Leggatt, M., \& Woodhead, G. (2016). Family peer support work in an early intervention youth mental health service. Early intervention in psychiatry, 10(5), 446-451.

Lenior, M. E., Dingemans, P. M., Linszen, D. H., De Haan, L., \& Schene, A. H. (2001). Social functioning and the course of early-onset schizophrenia: five-year follow-up of a psychosocial intervention. The British Journal of Psychiatry, 179(1), 53-58.

Lowyck, B., De Hert, M., Peeters, E., Wampers, M., Gilis, P., \& Peuskens, J. (2004). A study of the family burden of 150 family members of schizophrenic patients. European Psychiatry, 19(7), 395-401.

MacCourt, P. (2013). National guidelines for a comprehensive service system to support family caregivers of adults with mental health problems and illnesses: Mental Health Commission of Canada.

McCann, T. V., Lubman, D. I., \& Clark, E. (2009). First-time primary caregivers' experience of caring for young adults with first-episode psychosis. Schizophrenia bulletin, 37(2), 381-388.

McCann, T. V., Lubman, D. I., \& Clark, E. (2011). First-time primary caregivers' experience accessing firstepisode psychosis services. Early intervention in psychiatry, 5(2), 156-162.

McGorry, P. D. (1998). "A stitch in time"... the scope for preventive strategies in early psychosis. European archives of psychiatry and clinical neuroscience, 248(1), 22-31.

McGorry, P. D. (2015). Early intervention in psychosis: obvious, effective, overdue. The Journal of nervous and mental disease, 203(5), 310.

McGorry, P. D., Killackey, E., \& Yung, A. (2008). Early intervention in psychosis: concepts, evidence and future directions. World Psychiatry, 7(3), 148-156.

Patton, M. Q. (2015). Qualitative Research \& Evaluation Methods: Integrating Theory and Practice (4th ed.). Saint Paul, MN: Sage Publications, Inc.

Petrakis, M., Bloom, H., \& Oxley, J. (2014). Family perceptions of benefits and barriers to first episode psychosis carer group participation. Social Work in Mental Health, 12(2), 99-116.

Popping, R. (2015). Analyzing open-ended questions by means of text analysis procedures. Bulletin of Sociological Methodology/Bulletin de Methodologie Sociologique, 128(1), 23-39.

O'Sullivan, R. G. (2004). Practicing evaluation: A collaborative approach. Sage. 
Table 1

Details of respondents who attended meetings and responded to survey*

\begin{tabular}{|c|c|c|}
\hline Language & \multicolumn{2}{|c|}{$\mathrm{n}(\%)$} \\
\hline English & 22 & $(62 \%)$ \\
\hline French & 14 & $(38 \%)$ \\
\hline Type of Family/Caregiver & \multicolumn{2}{|c|}{$\mathrm{n}(\%)$} \\
\hline Mother & 22 & $(61 \%)$ \\
\hline Father & 6 & $(16 \%)$ \\
\hline Preferred not to answer & 8 & $(23 \%)$ \\
\hline \multicolumn{3}{|c|}{ Attendance since family member began treatment $\mathrm{n}(\%)$} \\
\hline Attended within first 6 months & 23 & $(52 \%)$ \\
\hline Attended after 6 months & 8 & $(18 \%)$ \\
\hline Preferred not to answer & 5 & $(23 \%)$ \\
\hline Total number of meetings attended & \multicolumn{2}{|c|}{$\mathrm{n}(\%)$} \\
\hline Between 5 and 20 & 15 & (34\%) \\
\hline More than 20 & 7 & $(16 \%)$ \\
\hline Less than 4 meetings & 7 & $(16 \%)$ \\
\hline Skipped this question & 7 & $(25 \%)$ \\
\hline Length of time attended meetings & \multicolumn{2}{|c|}{$\mathrm{n}(\%)$} \\
\hline A few months & 22 & $(50 \%)$ \\
\hline A few weeks (less than a month) & 5 & $(11 \%)$ \\
\hline One week & 4 & $(9 \%)$ \\
\hline One month & 1 & $(2 \%)$ \\
\hline Skipped question & \multicolumn{2}{|c|}{$4(23 \%)$} \\
\hline Present situation at home & \multicolumn{2}{|c|}{$\mathrm{n}(\%)$} \\
\hline Stable & 20 & (45\%) \\
\hline Just overcame a crisis & 14 & $(32 \%)$ \\
\hline Preferred not to answer & 2 & $(23 \%)$ \\
\hline
\end{tabular}

${ }^{*}$ Note. $N=36$ (an additional 8 respondents completed the survey but reported not having attended any meetings). 